\title{
Advantages of Negative Pressure Therapy in Local Diabetic Foot Treatment
}

\author{
MONICA MARILENA TANTU ${ }^{1}$, GEORGE MIHAIL MAN ${ }^{1}$, ALINA PAUNESCU는 ${ }^{1}$, CRISTINA FLORENTINA PLESA ${ }^{2}$, CAMELIA NICOLAE ${ }^{3}$, \\ LILIANA MARCELA ROGOZEA4, ALINA BISOC ${ }^{4 *}$, MARWA F. MOSTAFA ${ }^{5}$, ROXANA MARIA NEMES ${ }^{2}$, MAGDALENA DIACONU6 \\ ${ }^{1}$ University of Pitesti, Faculty of Sciences, Physical Education and Informatics, Medical Assistance and Physical Therapy \\ Department, 1 Targu din Vale Str., Pitesti, 110040, Romania \\ ${ }^{2}$ Titu Maiorescu University of Bucharest, Faculty of Medicine, 22 Dambovnicului Str., Bucharest, Romania \\ ${ }^{3}$ Carol Davila University of Medicine and Pharmacy, 8 Eroii Sanitari Blvd., 050474, Bucharest, Romania \\ ${ }^{4}$ Transilvania University of Brasov, Faculty of Medicine, 29 Eroilor Blvd., 500036, Brasov, Romania \\ ${ }^{5}$ Mansoura University, Faculty of Nursing, North Delta Sector, Mansoura, 35516, Egypt \\ ${ }^{6}$ University of Medicine and Pharmacy Craiova, 2 Petru Rares Str., 200349, Craiova, Romania
}

\begin{abstract}
Diabetic foot is a current public health problem and a late consequence of diabetes. Morbidity and mortality are significant, seriously affecting the patient's quality of life. Treatment of the diabetic foot is a long-lasting, highly resource-consumption process. Using negative pressure therapyleads to shorter hospitalization periods, better functional outcomes, significantly contributes to decreasing the number of amputations and improving patient's quality of life. 49 year-old patient is hospitalized with necrotizing at right foot and shank, neglected type II diabetes. It is performed amputation of atypical necessity, right leg, transtarsal, open stump. After successive debridements, negative pressure therapy is installed for a period of 24 days. This favors the formation of the granular bed, the remission of the infection, allowing grafting. The graft is partially integrated and plantar reconstruction is performed with sural reversal flap. The local and functional results are satisfactory, with the flap viability and the possibility of moving with support on the right leg, preventing the amputation of the shank. Negative pressure therapy has a multitude of advantages, it is preferable to conventional therapies, and it can have higher costs, but accelerates healing and improves the quality of life of the patient.
\end{abstract}

Keywords: diabetic foot, negative pressure therapy

Along with cardiovascular disease, lung cancer and tuberculosis [1], in the category of lifestyle related diseases, diabetes with its complications is an important cause of morbidity and mortality worldwide. It is estimated that in 2035 there will be 592 million of diabetics [2], and in 2040 there will be over 642 million [3], with a prevalence ratio of 1:10 [4], given that at the moment 387 million patients are diagnosed and $46.3 \%$ of the population with glucose metabolism disorders received no confirmation from the specialist [3].

With significant morbidity and mortality, seriously affecting the quality of life of the patient, the diabetic foot (DF) represents a current public health problem and a late consequence of diabetes, its prevalence being closely related to neuropathy and vascular damage in diabetes [ $5,6]$. Treatment of the diabetic foot is a long-lasting process, with high consumption of resources, both on the part of the patient and on the healthcare institutions that look after such a patient, including on the patient's family. It is appreciated that in the absence of surgery, the healing of the diabetic foot occurs on average within 12 weeks [7]. The implementation of new therapeutic methods for the diabetic foot, such as the vacuum system or negative pressure therapy (NPT), certainly leads to shorter hospitalization periods, better functional outcomes, significantly contributes to the decrease in the number of amputations and to improving the patient's quality of life [8].

\section{Case Study}

A 49-year-old patient from the countryside, chronic alcohol drinker, known for non-insulin-like type 2 diabetes, diagnosed for about 5 years, is brought into the emergency receiving unitin a very serious general condition, gangrene in the right foot. The haematological picture reveals important leukocytosis with neutrophilia (number of leukocytes $=18.77 \times 10^{3} / \mathrm{uL}$, neutrophil $=88.9 \%$ ), mild normometric anemia (hemoglobin $=10.5 \mathrm{~g} / \mathrm{dL}$, hematocrit $=31.9 \%$, average erythocyte volume $=87.6 \mathrm{fL}$ ), platelets within normal range $\left(243 \times 10^{3} / \mathrm{uL}\right)$, presepsine with increased value $(817 \mathrm{pg} / \mathrm{mL})$, nitrogen retention (creatinine $=1.85 \mathrm{mg} / \mathrm{dL}$, urea serum $=73 \mathrm{mg} / \mathrm{dL}$ ), elevated glycemic values (glucose $=500 \mathrm{mg} / \mathrm{dL}$ ), $\mathrm{pH}$ within normal rates $(=7.42)$. The general local clinical examination and the evaluation of the biological constants, lead to the diagnosis of gangrene with necrotizing right foot and shank, septic state, unbalanced type 2 diabetes. In the purulent secretion of the wound, it is isolated Enterobacter aerogenes. The general and local condition requires emergency surgery, under rahianesthesia, amputation of atypical necessity being performed, transtarsal, on the right leg, with open bone. Before the intervention, after the hydroelectolytic rebalancing, it is obtained the informed consent of the patient (fig. 1)

The general progression is rapidly favorable postoperatively, under insulin therapy, antibiotic therapy (cefoperazone+sulbactam $2 \mathrm{~g} / 12 \mathrm{~h}$, metronidazole $1 \mathrm{~g} / 12$ $h$ in the first $48 \mathrm{~h}$, subsequently replacing cefoperazone with meropenem - 500mg/8 $\mathrm{g}$ and ciprofloxacin $200 \mathrm{mg} /$ $12 \mathrm{~h}$ according to the antibiotic results, with the notice of the responsible with the use of antibiotics policy at the unit level), low molecular weight anticoagulant- fraxiparin 3800 u.i./12 $\mathrm{h}$, gastric antisecretor, antialgic, probiotics (as an 


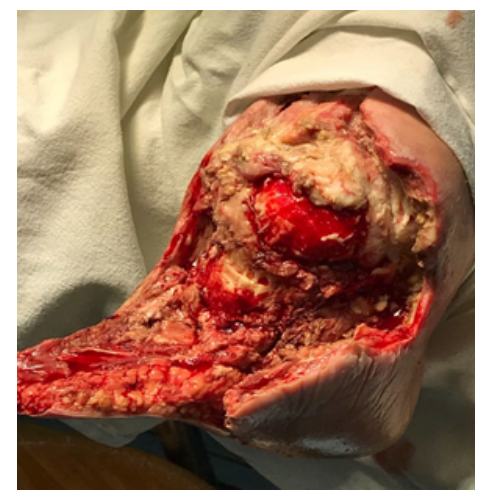

Fig. 1 Open bone, $48 \mathrm{~h}$ post transtarsal atypical amputation

adjunct in the prevention of clostridium difficile infection)[9], amino acid complex, protein hydrolysates, endovemous infusions with micromolecular solutions, group B vitamins, non-steroidal anti-inflammatory drugs, with decreased glycemic values (glucose $=183 \mathrm{mg} / \mathrm{dL}$ ), remission of leukocytosis (number of leukocytes $=8.73 \mathrm{x}$ $10^{3} / \mathrm{L}$ ), remission of nitrogen retension (creatinine $=0.96$ $\mathrm{mg} / \mathrm{dL}$, urea serum $=32 \mathrm{mg} / \mathrm{dL}$ ). The patient becomes cooperative, successfully passing even the alcohol withdrawal period as a result of specific psychiatric treatment. There are performed locally excisional debridements and dressings with antiseptic solutions and ointmentbased on argenic sulfadiazine successively, which allow approximation of the remaining plantar flap. Two weeks after transtarsal atypical amputation, negative pressure therapy is instituted to favor the formation of the granular bed for reconstructive treatment at the level of the stump. The patient is informed about this option, he is explained the mechanism of action of this system, highlighting the advantages of using this therapy and his consent is eventually obtained, both for the application of this type of local therapy as well as for the use of his medical imagery and data, for scientific purposes. Also, the patient is assured about the confidentiality of his data, the compliance with the norms of ethics in research, and it is reached a better communication relationship with the patient [10,11] (fig. 2).

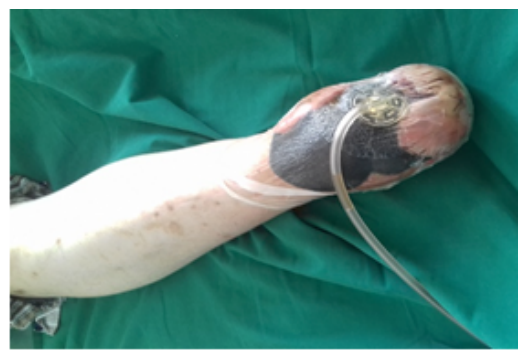

Fig. 2 Installing negative pressure therapy

The bandage kit is changed every 2-3 days, observing the progressive decrease in the amount of collected exudates, the beginning of wound granulation and marginal epithelialization. The patient is compliant with negative pressure local therapy; he does not accuse pain or discomfort caused by the limitation of mobility or of the equipment used (fig. 3).

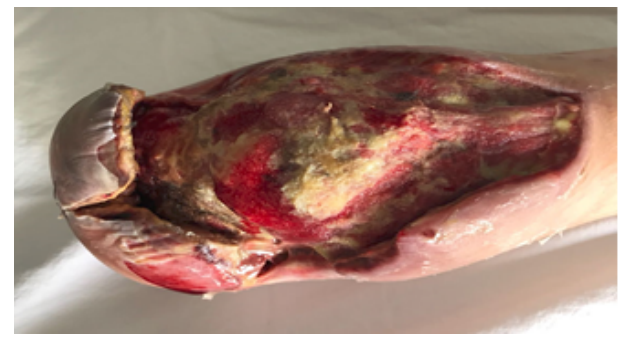

Fig. 3.Intermediate evolutionary stage under negative pressure therapy
It is continued the treatment with anticoagulant, peripheral vasodilators, vitamin therapy and glycemic control. After approximately 14 days of NPT it is revealed the maceration of the plantar flap edges in a $1.5 \mathrm{~cm}$ area, maintaining the viability of the plantar flap, but partial margin ischemia from the soft tissue defected area. In the wound area, devitalised tissue areas are reduced, and trophic granulations become obvious (fig. 4).

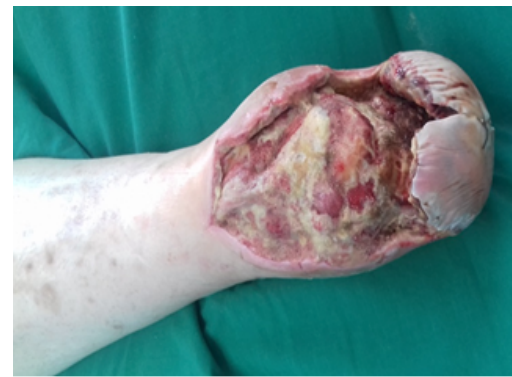

Fig. 4. Evolutionary stage with maceration of plantar flap margins and granular bed progression

For 3 days, NPT was suspended, constantly being made conventional wound dressings with argenic sulfadiazine as a debridement agent to monitor the plantar flap vasculature. NPT is restored for another 10 days, keeping the same rate of polyurethane sponge change. Local evolution is favorable, with the formation of a consistent granular bed at the level of the dorsal foot and $1 / 3$ inferior leg. It is performed the first reconstructive intervention, respectively the split skin graft, on the entire surface of the stump. The patient is externalized 10 days after grafting, the grafting being approximately $80 \%$, followed by dressings every 3-4 days in the ambulatory. The control performed one month after the surgery shows the grafting towards the plantar part and a good integration on the dorsal foot and shank. The partially favorable results of the grafting tend towards another reconstructive option, namely the plantar reconstruction with the sural reversed flap (fig. 5 and fig. 6).

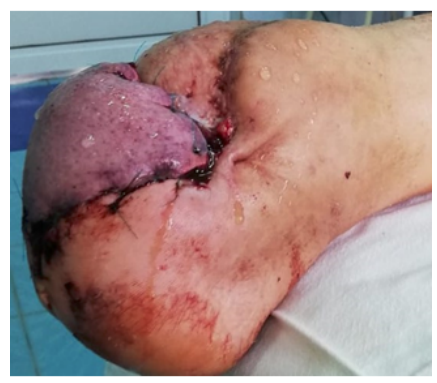

Fig. 5. Plantar reconstruction with sural reversed flap - incidence (a)

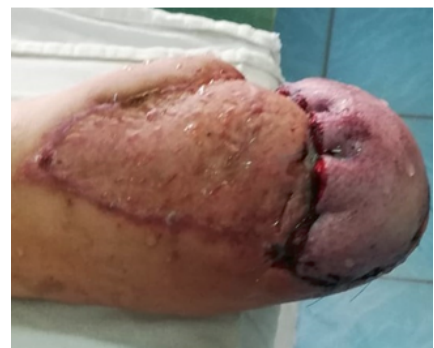

Fig. 6. Plantar reconstruction with sural reversed flap - incidence

(b)

The post-reconstruction evolution was favorable, the flap being viable and well integrated. The patient was discharged after 2 weeks of reconstructive surgery.

\section{Results and discussions}

The main complication of diabetes mellitus is diabetic neuropathy, which in turn is the determinant of lesions in the legs by loss of sensitivity that prevents effective control of the pressure distribution on the foot, especially when deformations occur. [12] Progression of lesions and their tremendous evolution, often completed by amputations at 
different levels of the foot, are supported by diabetic macro- and micro-angiopathy, as well as the history of ulcerations $[13,14]$.

Data on the prevalence of diabetic neuropathy and peripheral arterial disease are different depending on the period and country where the studies were conducted, and of course on the characteristics of the groups of diabetics studied. Thus, neuropathy was identified in $16 \%$ to $66 \%$ of patients with a prevalence influenced by the age of diabetes and a lack of effective glycemic control [15]. Peripheral arterial disease was assigned a prevalence of between 9.5 and $20.6 \%$ for diabetic patients compared to a range of 4.5 to $12.5 \%$ characteristic of the broad population with normal glucose tolerance [16].

Diabetic foot injury has an incidence of $15-25 \%$ throughout its life [17], with a recurrence rate of $50 \%$ to $70 \%$ after 5 years [ 18]. Worldwide, the prevalence of ulcers is estimated to be between $5.8 \%$ and $6 \%$ [19], the upper limit being exceeded in men with type 2 diabetes due to their increased predisposition (6.3\%) [20]. In Romania, studies of diabetic foot prevalence are inadequate, and those performed indicate that $14.85 \%$ of diabetics have problems with their legs [21].

Research has shown that the presence of foot lesions is a predictive mortality factor for the diabetic patient even at 10 years [19]. The diabetic foot generates $85 \%$ of amputations without a traumatic cause and corresponds to a mortality rate of $13-15 \%$ among diabetics [22]. The number of diabetic foot amputations has been steadily increasing and may be considered an indicator of the effectiveness of multidisciplinary diabetic foot management. In this respect, the only study conducted for a 5 year period in Romania revealed that 16,873 diabetic patients suffered 24,312 amputations, both in the foot and in the shank or thigh. [23]

In our service, in a 12-month analysis, a prevalence of $29.77 \%$ of the diabetic foot was identified in the total pathology treated, overcoming other pathologies such as skin tumors [24] and the amputations had a rate of $54.82 \%$ [25].

The appearance of foot lesions means marked physical and emotional impairment for the patient, social and professional disorder, and financial loss [26]. The costs of diabetic foot care are steadily rising, estimated at 20-40\% of the health care budget [27]. In 2015, such spending has reached $\$ 1.3$ trillion worldwide [28].

The diabetic foot recognizes several local treatment options: dressings with arthritic sulfadiazine debridement agents, excisional debridements, purulent collection evacuation, necrectomy, ostectomy, amputations at different levels, most often being required certain combinations of those mentioned above. Repeated surgical interventions, tremendous developments, often with the progression of necrotic lesions deplete the patient's biological and psychological resources, prolong the period of hospitalization, or lead to new admission episodes leading to unsatisfactory functional and aesthetic results, seriously affecting the quality of the patient's life. Applying a method of treatment, such as negative pressure therapy, that creates the least amount of discomfort to him, while hurrying healing is a good decision of the care team. The efficacy and safety of the negative pressure system has been highlighted in over 1,000 specialist papers [29], being an effective option for a wide range of wounds, especially for the chronic ones with low healing chances.

NPT is a non-invasive method with partially understood mechanisms of action [30], which is based on the exertion on the wound of a sub-atmospheric negative pressure within the range of $-50 \mathrm{mmHg}$ and $-175 \mathrm{mmHg}$, via polyurethane or polyvinyl alcohol sponge, fixed to the wound by an adhesive foil that provides a waterproof environment. The pressure and suction effect are provided by a digitally controlled pump, connected to the sponge by a flexible tube, and the exudates are collected in a receivertank with a capacity of $500 \mathrm{~mL}$ or $1000 \mathrm{~mL}$ [31]. NPT acts on interstitial fluid excess, thus reducing edema, improving tissue perfusion and removing infectious factors. Exercising mechanical forces on the tissues stimulates their granulation. The sponge introduced into the wound, under the effect of negative pressure, causes mechanical tissue microdeformation, which favors cellular proliferation $[32,33]$. For a diabetic foot patient, healing is not only about solving the infectious process or removing necrotic tissue, but also repairing residual defects through skin grafts and proximity or distant flaps. The success of such procedures is ensured by a viable granular bed capable of integrating the graft or flap. NPT has been shown to be effective in preparing the granular bed and reducing local infection [34].

The use of NPT in the diabetic foot patient is necessarily preceded by excisional debridements, the procedure recommended by diabetic foot care guides because it favors healing, transforming chronic wounds into acute ones by removing necrotic tissue [35]. Not all patients can benefit from NPT, with contraindications such as osteomyelitis, fistulization, necrosis, blood vessel exposures, tumor formations, or defects remaining after excision of tumors. It is also used with caution in patients with clotting disorders, given the high risk of bleeding, in those who have exposed bones and tendons, and in the situation where the blood infusion in the wound is severely impaired [36].

The advantages of NPT have been highlighted in multiple studies compared to conventional therapies (debridement dressings), appealing to various measurable indicators such as the evolution of ulcer size, the incidence of amputations, including the secondary ones, the period of granular bed formation, the number of hospitalization days, costs, but also to qualitative indicators, respectively the degree of comfort and improvement of the quality of life of the patient.

Thus, Blume [37] reported in his study that $14.3 \%$ of patients who received vacuum therapy had less than half of the time needed to cure ulcers with classic dressings, antiseptics and ointments.

An analysis of the incidence of amputations revealed that for 342 patients who were treated with NPT, an amputation risk of $4.1 \%$ compared to $10.2 \%$ was found in those with other types of therapy [34]. In another research, we observed the incidence of secondary amputation at a higher level due to the progression of the lesions and the ineffectiveness of the applied measures. The results were in favor of the NPT for which the incidence was 20\% compared to $24 \%$ for the group that received the classic treatment [38]. In the same study it was concluded that $76 \%$ of cases treated with NPT for one week developed granular tissue, while for conventional therapies the percentage was $28 \%$. In other studies [39,40], NPT favored the formation of the granular bed in $18.8 \pm 6$ days, respectively in $17.25 \pm 3.55$ days. Positive results were also found in reducing the size of ulcers and the number of hospitalization days. For the NPT group, the lesions initially had an average size of $40.44 \pm 2.82 \mathrm{~cm}^{2}$ and were reduced to $36.08 \pm 2.56 \mathrm{~cm}^{2}$. In the case of dressings with debridementagents, the diminution of the dimensions was from $38.52 \pm 2.73 \mathrm{~cm}^{2}$ to $37.63 \pm 2.86 \mathrm{~cm}^{2}$. Statistically significant was also the decrease in the number of 
hospitalization days ( $22.87 \pm 7.62$ for NPT compared to $32.53 \pm 10.17$ for other therapies, $p=0.02$ ) [38].

The study conducted by Karatepe et al [41], consisting of the application of a 36-items questionnaire on physical and mental health, revealed the real benefits of NPT for the quality of life of the patient, compared to the control group that followed conventional local therapies for treating the diabetic foot.

In the case presented, the advantages of NPT use in the local management of the diabetic foot are obvious: obtaining a 2/3 graftable granular bed on the transtarsal atypical amputation stump with integral graft in the area, reducing the stress generated by the daily changes in the case of conventional dressings imposed by massive exudates, amelioration of the local microbial condition (subsequently, the NPT culture from the plague was negatively affected). It is also important that the obtained functional result is superior (preservation of the ankle and hind foot) compared to the situation in which the amputation of the shank is chosen, the patient being able to move with support on the right leg, after prosthesis with orthopedic boot. Moreover, as he partially kepthis foot and the stump is functional through the orthopedic shoe port, the patient can reintegrate much easier into the socialfamilial life without feeling the loss of self-esteem due to impaired body image and limited capacity to meet their basic needs. The therapeutic option of amputation would have meant to reduce the hospitalization period to about 2 weeks, but the post-intervention patient's quality of life would have been much lower.

The NPT efficiency is conditioned by the patient's compliance, which makes it imperative, before installing the dressing kit, an objective appreciation of his ability to understand and comply with the conditions of the therapy. Good information of the patient on the rate of changes of the dressing, at the sethe will have to adopt, with significant limitation of mobility, on the advantages and possible local complications (maceration of the healthy skin around the ulcers, pain) will reduce the risk of his pulling out the negative pressure device or causing additional lesions. Our patient was compliant, and the NPT provided the necessary conditions for reconstructive surgery with good functional results, preventing amputation of the shank.

\section{Conclusions}

NPT is an easy, non-invasive treatment for acute and chronic ulcers of the diabetic foot with a variety of advantages, which is clearly preferable to conventional therapies, although it may have higher costs, but which brings real benefits to the quality of life of the diabetic patient.

\section{References}

1.NITU FM., OLTEANU M., STREBA CT. et al., Rom J Morphol Embryol 2017, 58(2): 385-392

2.TOOSIZADEH N, MOHLER J, ARMSTRONG DG, TALAL TK, NAJ AFI B. PLoS One. 2015; 10(8):e0135255.

3.HAN CHO N., INTERNATIONAL DIABETES FEDERATION (IDF). Available from: http:// www.idf.org/sites/default/files/Atlasposter2014 EN.pdf.

4.*** INTERNATIONAL DIABETES FEDERATION. IDF Diabetes Atlas International Diabetes Federation, Brussels, Belgium, 2013, 6 5.SLATER RA, LAZAROVITCH T, BOLDURI, RAMOTY, BUCHSA, WEISS M, HINDI A, RAPOPORT MJ. Diabet Med, 2004, 21(7):705-70

6.SI LIU, CHAO-ZHU HE, YAN-TING CAI, QIU-PING XING, YING-ZHEN GUO, ZHI-LONG CHEN, JI-LIANG SU, LI-PING YANG, Therapeutics and Clinical Risk Management 2017:13 533-544

7.RAMSEY SD, NEWTON K, BLOUGH D, et al. Diabetes Care 1999;22:382-387
8.ASHRAF HM. Journal of Surgery. Special Issue: Postoperative Pain Syndrome. Vol. 3, No. 2-1, 2015, pp. 31-35. doi: 10.11648/j.js.S. 2015030201.17

9.TANTU, M.M., MAN, G.M., PAUNESCU, A., et al., Rev. Chim. (Bucharest), 69, no.11, 2018, p. 3001-3005

10.POPESCU IG, SECHEL G, LEASU FG, et al., Rom J Morphol Embryol 2018, 59(3): 1001-1005

11.CONSTANTIN DA, CIORICEANU IH, TANTU MM, etal., Rom J Morphol Embryol 2017, 58(3):1121-1125

12.CARAVAGGI C, DE GIGLIO R, PRITELLI C, et al., Diabetes Care, 2003, 26(10):2853-2859.

13.CHAPMAN MJ, CROCKETT SC, PURVIS TE, ANDERSON MJ, WHITTAKER PL, BHATTACHARJEE R, MARSHALL TP, NARENDRAN P, NIRANTHARAKUMAR K. J Diabetes Metab, 2013, 4(8):299.

14.VAN ACKER, K., WEYLER, J., DE LEEUW, I. Acta Clinica Belgica,2001, 56, 21-31

15.BOULTON AJ. Diabetes/Metabolism Research and Reviews. 2000 Sep 1;16(S1):S2-5

16.SELVIN E, ERLINGER TP. Circulation. 2004 Aug 10;110(6):738-43

17.CENTERS FOR DISEASE CONTROL AND PREVENTION. 2014.

Available from: http://www.cdc.gov/diabetes/pubs/statsrepor t14/ national-diabetes-report-web.pdf

18.BOULTON AJ ., Medicine. 2010; 38(12):644-648

19.JEFFCOATE WJ, VILEIKYTE L, BOYKO EJ, ARMSTRONG DG, BOULTON AJ M., Diabetes Care 2018; 41:645-652

20.ARMSTRONG DG, BOULTON AJM, BUS SA. N Engl J Med 2017;376:2367-75

21.BONDOR IC, VERESIU IA, FLOREA B, VINIK EJ, VINIK AI, GAVAN NA., J ournal of Diabetes Research.2016, doi: 10.1155/2016/5439521

22.KVITKINA T, NARRES M, CLAESSEN H, et al., Syst Rev. 2015;4:74.

23.VERESIU IA, IANCU SS, BONDOR IC., Diabetes Research and Clinical Practice, 2015, 109(2) :293-298. doi: 10.1016/j.diabres.2015.05.020

24.TANTU MM, BELU E, MAN GM. etal., Rom J Morphol Embryol 2014, 55(3):803-809

25.TANTU MM, MAN GM, ROGOZEA LM. etal., Rom J Morphol Embryol 2018, 59(3): 895-902

26.LUCAS C., CLASSEN J., HARRISON D., DEHAAN R., 2002; 15(1):1723.

27.INTERNATIONAL DIABETES FEDERATION. IDF DIABETES ATLAS, 7th edn., 2015. http:// www.diabetesatlas.org

28.BOMMER C, HEESEMANN E, SAGALOVA V, et al., Lancet Diabetes Endocrinol 2017;5:423-430

29.VIG S, DOWSETT C, BERG L et al., J Tissue Viability, 2011, 20: S1e$\mathrm{S} 18$

30.SCHINTLER MV, Diabetes Metab Res Rev. 2012, Suppl 1:72-7. doi: 10.1002/dmrr.2243

31.ULUSAL AE., SAHIN MS., ULUSAL B., ÇAKMAK G., TUNCAY C., Acta Orthop Traumatol Turc 2011;45(4):254-260

32.SAXENA V, HWANG CW, HUANG S, EICHBAUM Q, INGBER D, ORGILL DP., Plast Reconstr Surg 114:1086-1096, 2004

33.GREENE AK, PUDER M, ROY R, ARSENAULT D, KWEI S, MOSES MA, ORGILL DP., Ann Plast Surg 56:418-422, 2006

34.ARMSTRONG DG, LAVERY LA., Lancet. 2005;366(9498): 1704-1710. 35.DUMVILLE JC, HINCHLIFFE RJ, CULLUM N, GAME F, STUBBS N, SWEETINGM, PEINEMANN F. Cochrane Database of Systematic Reviews 2013, Issue 10. Art. No.: CD010318. DOI: 10.1002/14651858. CD010318.pub2

36.GUY H, GROTHIER L.,Nursing Times; 2012, 108; 36, 16-20

37.BLUME P., ALTERS ] ., PAYNE W., AYALA J ., LANTIS ] ., Diabetes Care 31:631-636, 2008

38.BAYOUMI A., AL-SAYED A., AL-MALLAH A., The Egyptian Journal of Hospital Medicine, 2018, Vol. 72 (3):4054-4059

39.SEPULVEDA G, ESPINDOLA M, MAUREIRA M, et al., Cir Esp. 2009;86(3):171-177.

40.VAIDHYA N, PANCHAL A, ANCHALIA MM., Indian J Surg. 2015;77 (Suppl 2): 525-529

41.KARATEPE 0, EKEN I, ACET E, et al., Acta Chir Belg. 2011;111(5):298302

Manuscript received: 21.12 .2108 